International Journal of Engineering \& Technology, 9(3) (2020) 602-606
International Journal of Engineering \& Technology
SPC
Website: www.sciencepubco.com/index.php/IJET
Research paper

\title{
Evaluation of the thermal performance of a box type solar cooker in the rainy season in a sub-Saharan country
}

\author{
D. Soro ${ }^{1 *}$, Y. Doumbia ${ }^{2}$, B. Marí $^{3}$, B.Fofana ${ }^{1}$, N. A. YAO ${ }^{1}$, S. Touré ${ }^{2}$, B. Aka ${ }^{4}$ \\ ${ }^{1}$ Département des Sciences et Technologie, Ecole Normale Supérieure (ENS) d'Abidjan, Côte d'Ivoire \\ ${ }^{2}$ Laboratoire d'Energie Solaire, Université FHB D'Abidjan-Cocody, Côte d'Ivoire \\ ${ }^{3}$ Departament de Física Aplicada-IDF, Universitat Politècnica de València, Spain \\ ${ }^{4}$ UFR-SFA, Université Nangui Abrogoua, d'Abidjan, Côte d'Ivoire \\ *Corresponding author E-mail: donafologosoro@yahoo.fr
}

\begin{abstract}
This article deals with the calculation of the performance parameters of a box-type solar cooker in a sub-Saharan country in the rainy season where the solar activity is considerably attenuated because of the numerous cloudy periods. The various tests were carried out at the Labora-tory of Fundamental and Applied Physical Sciences of the École Normale Supérieure (ENS) in Abidjan. During these cooking tests, the illuminance was measured. The temperatures of the ambient air and of various places of the solar cooker were also recorded. Illumination measurements made with an EPPLEY type pyranometer made it possible to determine the average illuminance which oscillates between $636.98 \mathrm{w} / \mathrm{m}^{2}$ and $517.91 \mathrm{w} / \mathrm{m}^{2}$ depending on the day. The average energy efficiency of the cooker has been calculated for the cooking of several foods. It varies between $20.48 \%$ to $26.59 \%$. The overall loss coefficient is between 5.63 and 5.82 . The results obtained for these tests are satisfactory and very encouraging, especially since they were carried out in the rainy season.
\end{abstract}

Keywords: Box Solar Cooker; Solar Irradiance; Parameters; Thermal Performances; Heating.

\section{Introduction}

During these past few years, most of the sub-Saharan African countries have experienced rapid population growth and considerable urbanization. This leads to increased demand for energy. At the culinary level, gas (LPG) is used in big cities, and especially in residential district. But this gas is more and more expensive and sometimes out of stock. In low-end neighborhoods, charcoal and firewood are largely used for cooking food. In the countryside, hamlets and isolated villages, food is always cooked with fuelwood or charcoal for both family and collective needs. In Côte d'Ivoire, this woody energy source is widely used. Its participation in energy needs is estimated at around $76 \%$ in 2008 [1]. It is mainly used in the form of firewood and charcoal. The domestic use of plant cover as firewood or charcoal and especially the extraction of wood fuel increases with the increase of the population.

This is at the root of deforestation, environmental pollution and global warming [2]. Cooking food is very expensive when you use conventional energy sources and has disastrous consequences on the ecosystem when you use the wood from the few remaining shrubs [3]. To overcome these problems, one of the natural and easy alternatives is obviously the use of the energy transported by solar radiation. Côte d'Ivoire has a huge solar deposit. The average daily sunshine varies between 3 and $5 \mathrm{kWh} / \mathrm{m}^{2}$ depending on the region and a duration of sunshine of 6 hours [1]. This non-polluting and free energy can be converted into energy useful for cooking food thanks to solar cookers or solar concentrators. It is a promising option capable of being one of the main sources of energy in the domestic sector [4,5]. Several studies have been carried out on concentrators whose reflector is coated with a mirror [6].

J. Chasseriaux has classified the different types of concentrator from the geometric concentration coefficient according to temperature ranges [7]. We distinguish:

- The weak concentrators. Their concentration coefficient $\mathrm{C}$ varies from 1 to 10 , and the temperature of the absorber can reach $150^{\circ}$ C;

- Medium concentrators. Their concentration coefficient $\mathrm{C}$ is between 10 and 100, and the temperature of the absorber is around 300 ${ }^{\circ} \mathrm{C}$;

- $\quad$ Strong concentrators: These have a concentration coefficient greater than 100 , and the temperature of the absorber is above $300{ }^{\circ} \mathrm{C}$. The objective of this work is to determine the performance parameters of a box-type cooker on the basis of the cooking carried out during the days of experimentation. s. 


\section{Dispositif experimental}

The cooker is mainly made from plywood sheets, flat mirrors and an absorber made of blackened $0.8 \mathrm{~mm}$ thick galvanized sheet metal. With this type of system, we seek to raise the temperature of the metal plate that will support the kitchen utensil (Figure 1a) when it is exposed to solar radiation. For this, we place the metal plate in a thermally insulated box on the back with a layer of glass wool carefully wrapped in aluminum foil. In the internal volume of the box, four mirrors are placed, each fixed to one side of the box and inclined by 65 ${ }^{\circ}$ relative to the bottom of the box, so that it can reflect all of the incident solar radiation passing through the opening surface of the box towards the absorber. To create the greenhouse effect and minimize heat loss from the heating plate to the environment, there is a transparent cover $10 \mathrm{~mm}$ thick on the front side. This cover is placed directly on the edges of the internal mirrors which are provided with a rubber seal. This configuration allows easy opening of the range to gain access to the hot plate. To reach very high temperatures, it is necessary to increase the radiation absorbed by the heating plate. For this, we use a flat mirror reflector arranged on a plywood plate which is fixed on the upper edge of the box in Figure 1b. The fixing is ensured by aluminum hinges. These hinges allow the reflector to be oriented when the system is exposed to the sun. Outside the operating moments, the reflector is folded down and the cooker is closed Figure $1 \mathrm{c}$. During the period of use of the solar cooker, it is oriented so that the direct solar radiation is perpendicular to its surface. opening. This technique allows better capture of solar radiation and a longer duration of daily use because the operation of the cooker can be obtained from sunrise.
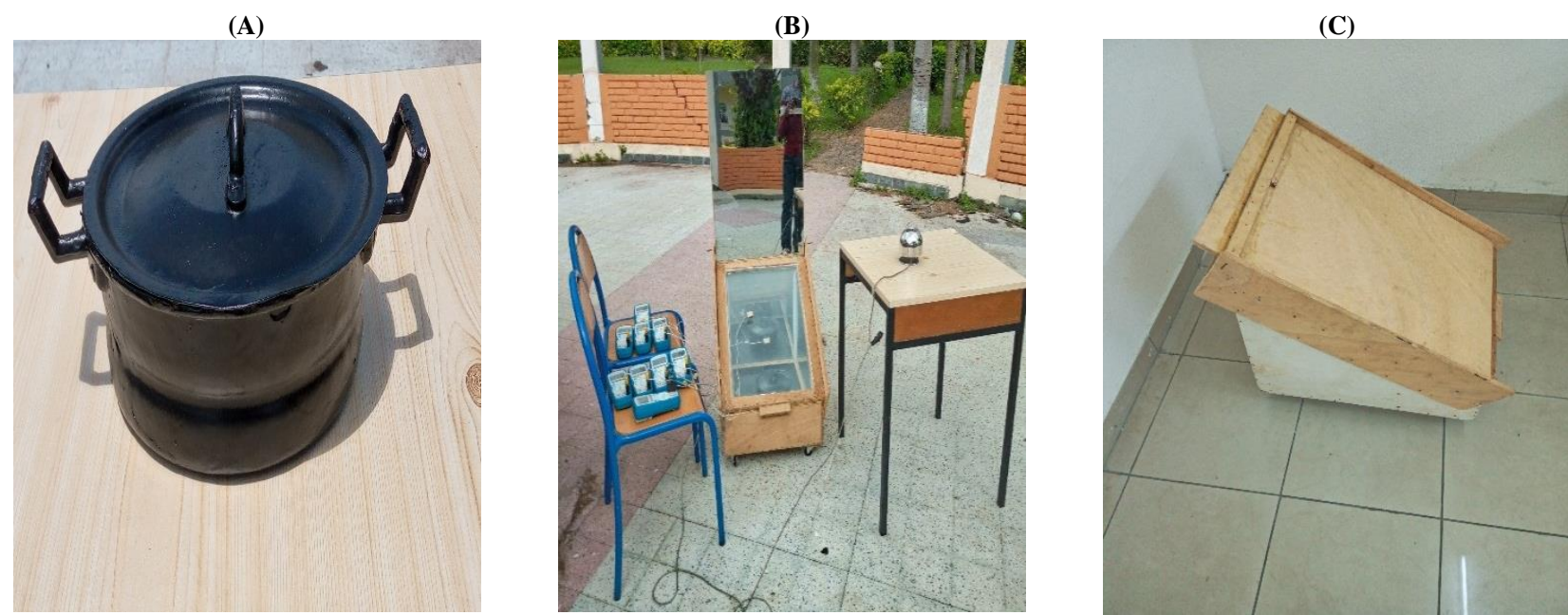

Fig. 1: A) Photograph of the Kitchen Utensil; B) Photograph of the Solar Cooker in Operating Mode, C); Photograph of the Solar Cooker with the Reflector Turned Down.

(A)

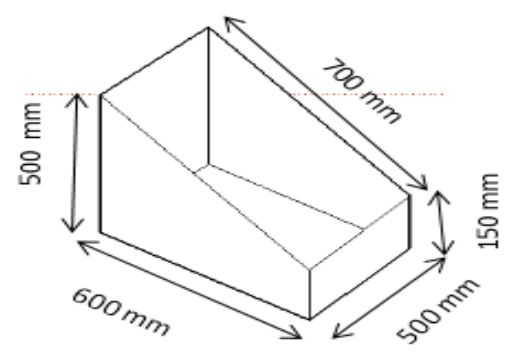

(B)

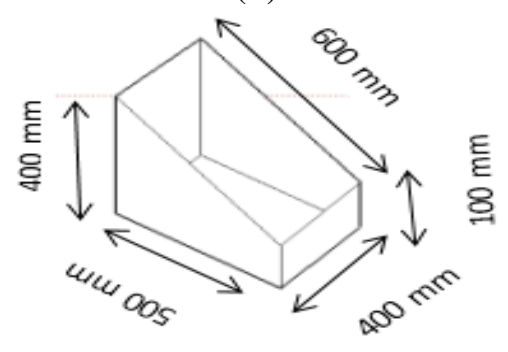

Fig. 2: Schematic Diagram of Box Solar Cooker.

\section{Experimental procedure}

During our various cooking tests, two-time variables are measured: temperature and solar illumination.

\subsection{Measurement of the illumination}

Irradiance is a term used to quantify the power of electromagnetic radiation per unit of area. In the international system, it is expressed in watt per square meter $\left(\mathrm{W} / \mathrm{m}^{2}\right)$. To measure the solar irradiance that reaches the earth's surface, we used a pyranometer. When it's exposed to the sun on a horizontal plane, it behaves like a generator and delivers an electromotive force (f. e. m..) proportional to the illuminance received. The measures were carried out with an EPPLEY type pyranometer, with a conversion coefficient $\mathrm{k}$ equal to $10.41 \mathrm{mV} / \mathrm{W} / \mathrm{m}^{2}$ and with an error in the measured illumination $\pm 10 \mathrm{~W} / \mathrm{m}^{2}$, every $10 \mathrm{~min}$. Figure 3 shows this pyranometer connected to the terminals of a digital multimeter with digital display used in voltmeter mode. The f. e. m. measured allows the illumination to be determined by calculation using the equation:

$E=\frac{U}{k}$

Where:

E: illuminance received $\left(\mathrm{W} / \mathrm{m}^{2}\right)$

$\mathrm{U}$ : electromotive force $(\mathrm{mV})$ 
$\mathrm{k}$ : Conversion coefficient $\left(\mathrm{V} / \mathrm{W} / \mathrm{m}^{2}\right)$. It depends on the type of pyranometer.

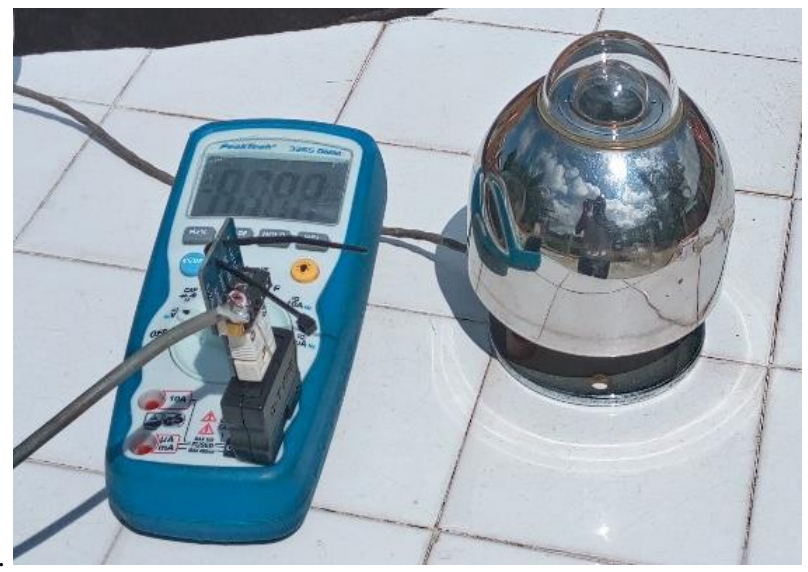

Fig. 3: Photograph of the Pyranometer Connected to the Multimeter's Terminals.

\subsection{Measurement of temperatures}

To meet the needs of this study, thermocouples were installed in different places of the cooker. They are embedded in plywood supports thus allowing to fix them on the given surfaces (Figure 4). For better exposure of the absorbent plate to solar radiation, the cooker is oriented so that the azimuth angle of the cooker opening surface is equal to the solar azimuth angle. This orientation is obtained manually over time steps of 5 minutes in order to be able to accept the hypothesis of a continuous orientation of the radiation at the surface. In order to study the behavior of the solar cooker, experimental tests were carried out and data recorded every 10 minutes. The ambient air (Ta), absorber (Tp), indoor air (Tr) and cooking temperature (Tw) temperatures were measured.

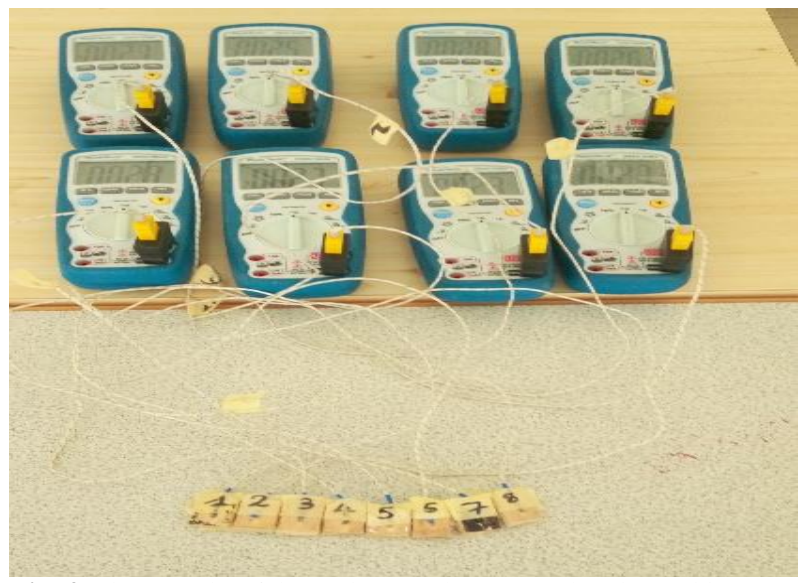

Fig. 4: Photographs of the Probes Used Connected to the Multimeters.

\subsection{Energy balance of the cooker}

If we have the solar irradiance that reaches the earth's surface, then the fraction of the solar light absorbed by the absorbent plate (horizontal) after crossing the glazing is calculated using the expression:

Qabs $=\tau$ capGt

With,

$\tau \mathrm{v}$ : Transmission factor of the reflector,

$\alpha p$ : Absorption factor of the absorber,

Gt: The overall lighting incident on the cooker $\left(\mathrm{W} / \mathrm{m}^{2}\right)$

A part of the energy absorbed is transferred into the environment in the form of thermal energy mainly by convection, radiation and conduction. The fraction of the solar irradiance absorbed by the absorbent plate is partially recovered by the kitchen utensil in the form of heat. We denote it $\mathbf{Q u}$. However, the solar cooker is subject to heat loss. These losses will be noted Qp. So, we have:

$\mathrm{Qabs}=\mathrm{Qu}+\mathrm{Qp}$

In addition, we have:

$\mathrm{Qp}=\mathrm{UL}(\mathrm{Tp}-\mathrm{Ta})$

Ta: ambient air temperature

Tp: Absorber temperature $(\mathrm{Tp})$

UL is the overall loss coefficient defined as the sum of the front, side and rear loss coefficients. 
$\mathrm{UL}=\mathrm{Uav}+\mathrm{Uar}+\mathrm{Ula}$

By replacing equation (3) in equation (2), we obtain the expression of useful energy

$\mathrm{Qu}=\tau \mathrm{v} \alpha \mathrm{pGt}-\mathrm{UL}(\mathrm{Tp}-\mathrm{Ta})$

\subsection{Efficiency}

The expression of the instantaneous yield of the sensor as a function of the average temperature of the absorbent plate is given by equation (6) according to Guedira et al, [8]. $\mathrm{y}=\tau \mathrm{vapGt}-\mathrm{UL}(\mathrm{Tp}-\mathrm{Ta}) / \mathrm{Gt}(7)$

\section{Results and discussion}

\subsection{Measurement of global illumination and temperatures}

During our various cooking tests, two time variables are measured: temperature and solar illumination. These various measurements made every 10 minutes made it possible to draw histograms for the lighting and curves for the temperatures. The histograms show the variation of the illumination and the curves the evolution of the temperatures during the various experiments. The cooking tests for yams and eggs started in the morning. The eggs were cooked on 10/25/2019 and the yams were cooked on 10/30/2019. As for the tests for cooking spaghetti and rice, they take place in the evening from 1:00 respectively on October 29 and 30, 2019. Based on the histograms obtained, we note remarkable drops in lighting by moment due to the intermittent passing of the clouds reminding the period of the rainy season. The shape of the measured temperature graphs is not uniform. These curves except for that of the ambient air undergo disturbances due to cloudy passages (Figure 5 and Figure 6). These tests made it possible to highlight several phenomena. Among other things, we have radiation conduction. The sun emits radiation which is absorbed by the absorber painted black which converts it into heat. The absorber thus heated, in contact with the kitchen utensil which is cold, will transfer part of its heat. It is a heating by heat transfer which is carried out by the contact of two materials of different temperatures. This is heat transfer by conduction. This fraction of heat is absorbed by the food inside the cookware. In addition, when the absorbent plate is irradiated on its upper face, by natural convection, it transmits a large part of the absorbed radiation which it converts into heat towards the indoor air. But during this transfer, there are losses. The temperatures of the absorber are constantly higher than those of kitchen utensil. The temperature curves of the absorber (Tp) are therefore permanently above those of the cooking (Tw). The greenhouse effect is not negligible. Despite the insufficiencies in terms of solar radiation (partly cloudy sky) ) the indoor air temperature has exceeded the threshold of $106^{\circ} \mathrm{C}$, close to that of the absorber which is $115^{\circ} \mathrm{C}$. All cooking tests respect the maximum cooking time for food given by "Solaire international cockers" [9].

(A)

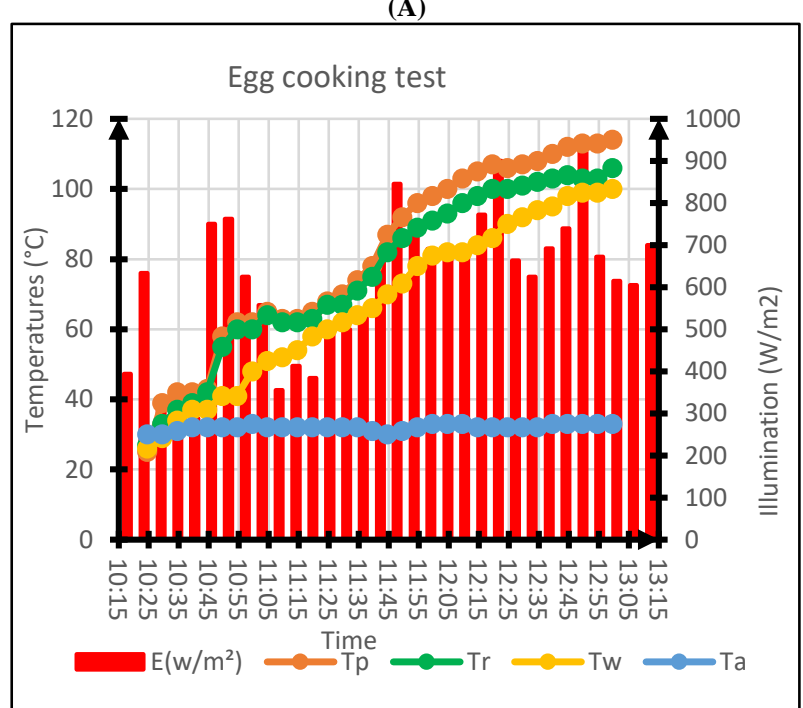

(B)

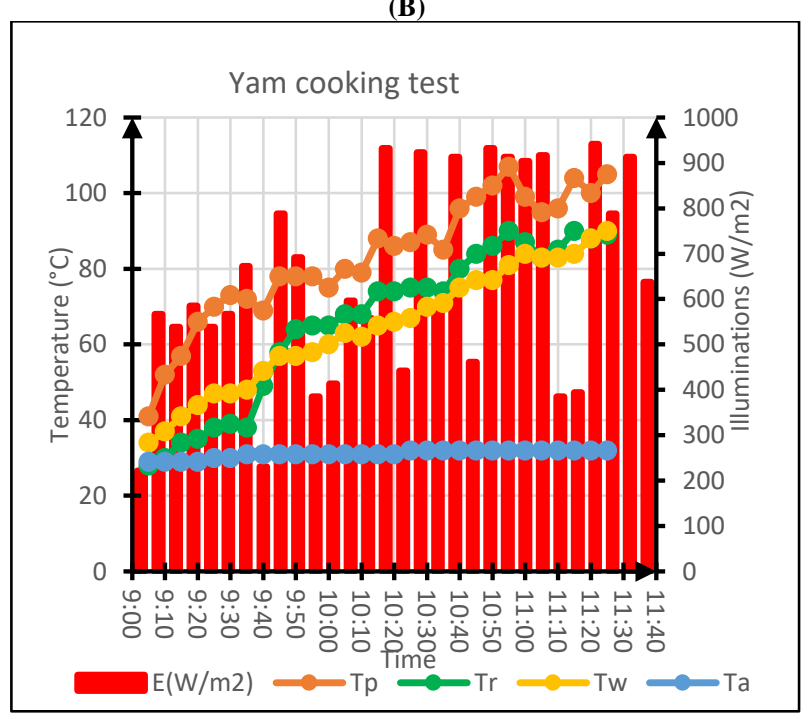

Fig. 5: Histogram of the Illumination and Evolution Curves of the Temperatures of the Ambient Air, the Absorber, the Indoor Air and the Utensil as A Function of the Time for Cooking the Eggs and the Yam. 
(A)

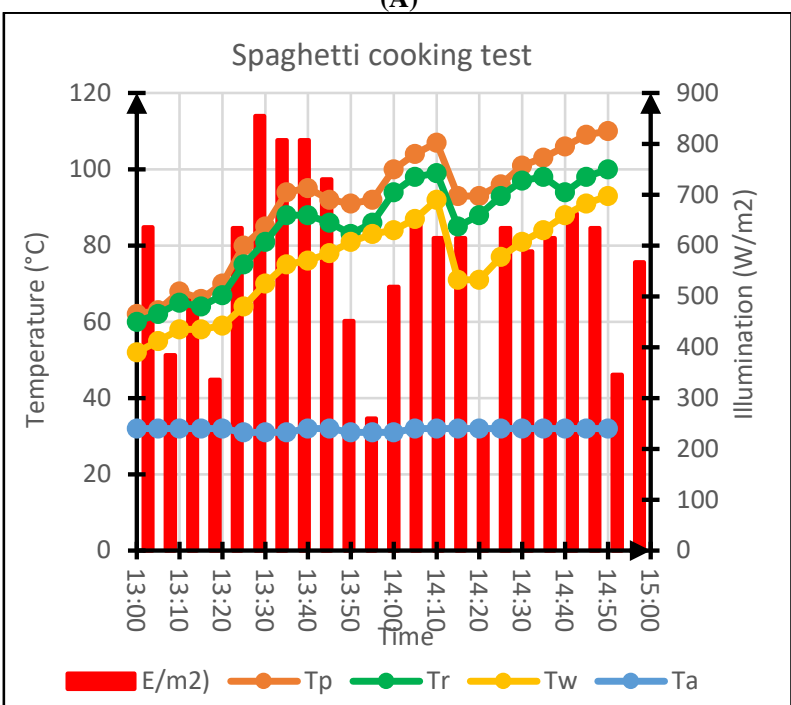

(B)

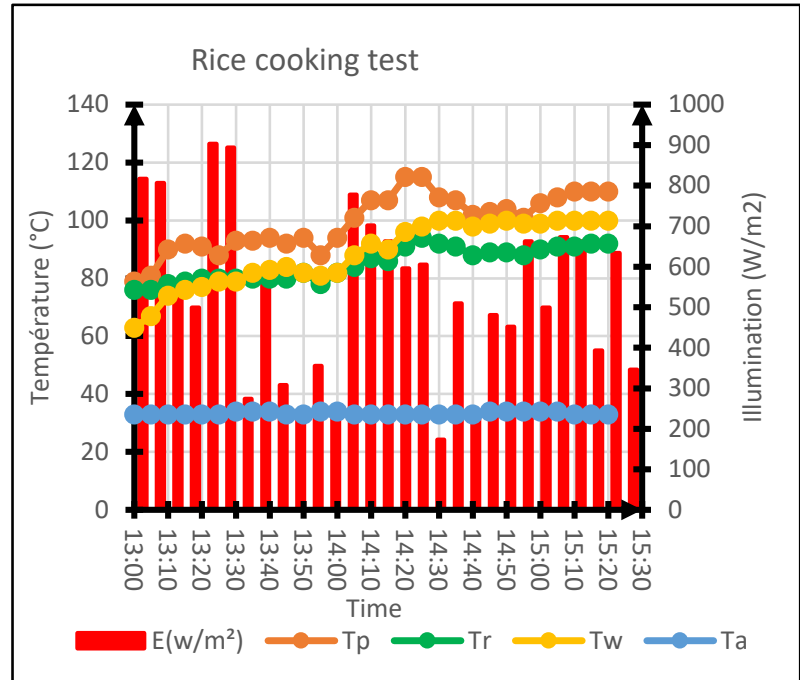

Fig. 6: Histogram of the Illumination and Evolution Curves of the Temperatures of the Ambient Air, the Absorber, the Indoor Air and the Utensil as A Function of the Time for Cooking the Spaghetti and the Rice.

\subsection{Overall loss coefficient and energy efficiency}

To determine the performance of the box type cooker, we calculated the overall loss coefficient and the efficiency during cooking tests. These thermal performance parameters obtained are given in the table. The best efficiency is obtained when cooking yams. It is $25.59 \%$. However, all the tests have a efficiency greater than $20 \%$. Regarding the overall loss coefficient is relatively low. It is between 5.63 and 5.82. These low values indicate good insulation of the solar cooker.

Table: Performance Parameters of the Box -Type Cooker When Cooking Foodstuffs

\begin{tabular}{llll}
\hline Foodstuffs & Illumination $\left(\mathrm{w} / \mathrm{m}^{2}\right)$ & Overall loss coefficient $\left(\mathrm{w} / \mathrm{m}^{2}{ }^{\circ} \mathrm{C}\right)$ & Cooker efficiency $(\%)$ \\
\hline Egg & 609.77 & 5.70 & 23.73 \\
Spaghetti & 517.91 & 5.95 & 20.48 \\
Yam & 636.98 & 5.63 & 25.59 \\
Rice & 533.76 & 5.82 & 22.56 \\
\hline
\end{tabular}

\section{Conclusion}

This article presents the results of an experimental study evaluating the thermal performance of a box-type solar cooker with an inclined opening surface carried out in a sub-Saharan country during the rainy season. Tests have shown that using this system we can prepare foodstuffs with reasonable cooking times. The configuration adopted for its opening surface allows to have a hot plate that ensures good exposure to the solar radiation of the kitchen utensil used. The average power absorbed by the solar cooker oscillates between $446.76 \mathrm{w} / \mathrm{m} 2$ and $533.15 \mathrm{w} / \mathrm{m} 2$, the efficiency exceeds $20 \%$ in all cases while the overall loss coefficient is greater than 5.5. This box-type solar cooker is therefore a cooking instrument that can be perfectly integrated into the daily lives of populations. It introduces another way of preparing foodstuffs, using a form of energy that respects the environment and ensures sustainable development. It makes it possible to make real savings both in terms of money and in terms of energy consumed. The natural environment is also a winner, since greenhouse gas emissions are reduced. From this observation, the results obtained and the parameters calculated we can conclude that this box-type solar cooker is well suited for cooking various foods in the rainy season.

\section{References}

[1] S. Gnigbognima, P. N'cho, "Forum Régional sur l'initiative énergie solaire de la CDEAO, Présentation de la Côte d'Ivoire", (2010).

[2] PNUD : "Formuler des scénarios climatiques pour éclairer les statistiques de développement résilient au climat. Guide à l'intention des praticiens ", (2011).

[3] A. Dizier and F. Pignon, "Manuel de cuisson solaire, Edition commune SCI / iD COOK", Paris, France, (2005).

[4] UNDP. "World energy assessment 2000 - energy and the challenge of sustainability. New York: UNDP"; (2000).

[5] Panwar NL, Kaushik SC, Kothari S., "'Role of renewable energy sources in environmental protection: a review". Renew Sust Energy Rev (2011). https://doi.org/10.1016/j.rser.2010.11.037.

[6] D. SORO, Modibo S., Siaka T., B. Marí, B. Aka, 'Comparative cooking tests of two parabolic and elliptical solar concentrators at covered fireplaces located in a greenhouse area", International Journal of Materials Engineering and Technology, (2019) https://doi.org/10.17654/MT018020067.

[7] J.M. Chassériaux, "Conversion thermique du rayonnement solaire", Bordas Paris (1984).

[8] Guedira,A Benallou.A 'Procédure de qualification des capteurs plan sous ensoleillement naturel au Maroc", Revue des Energies Renouvelables, journées de thermique (2001).

[9] Solar Cookers International, www.solarcooking.org/francais/Plans-fr.pdf, (consulted on 12/02/2020). 